\title{
GENOME-WIDE IDENTIFICATION AND CHARACTERIZATION OF THE SBP GENE FAMILY IN EUCALYPTUS GRANDIS
}

\author{
BUYUK, I. \\ Department of Biology, Faculty of Science, Ankara University, Ankara, Turkey \\ (e-mail: buyuki@ankara.edu.tr; phone: +90-312-212-6720 (1390); fax: +90-312-223-2395) \\ (Received $9^{\text {th }}$ Jul 2018; accepted $6^{\text {th }}$ Sep 2018)
}

\begin{abstract}
SQUAMOSA promoter binding proteins (SBP) are a group of plant transcription factor (TF) families that play an important role in plant development and defence response. Genome-wide investigations of SBP genes have been carried out in many plant species, however this is the first comprehensive report on the identification and characterization of SBP genes in Eucalyptus grandis (E. grandis). According to the results herein, 16 SBP genes from $E$. grandis were identified and SBP proteins were clustered in eight clades. 16 SBP genes were presented to distribute 7 out of 11 chromosomes and three segmental duplicated gene couple were found throughout the entire genome of E. grandis. A total of 15 conserved motifs were described and 3 out of 15 were found to be conserved among all Egrandis_SBP proteins, due to forming of SBP domain which is essential for the function of SBP proteins. Gene structures of all Egrandis_SBP genes were investigated and the estimated number of exons among all genes extended from 2 to 11 . According to the synteny analysis, it was seen that homologs of E. grandis genes were found in corresponding syntenic blocks of Arabidopsis thaliana and Vitis vinifera. Digital gene expression analyses showed that most of the Egrandis_SBP genes were highly expressed in shoot tips, young leaf, xylem, mature leaf, immature xylem and phloem tissues of E. grandis. Taken all together, the results of this study will provide an important source for literature and further works.
\end{abstract}

Keywords: bioinformatic approach, phylogeny, RNAseq, digital gene expression

\section{Introduction}

Squamosa promotor binding proteins (SBPs) are transcription factor (TF) genes that are only found in plants, their presence have not been verified in animals and prokaryotic organisms thus far (Klein et al., 1996; Hou et al., 2013). One common feature in members of the SBP TF family is the presence of 76 aa DNA-binding domain which have been called: SBP domain containing two zinc fingers (Cys-Cys-His-Cys and Cys-Cys-Cys-His) (Klein et al., 1996; Yamasaki et al., 2004; Pan et al., 2017).

They were first discovered in Antirrhinum majus (Klein et al., 1996) and their first comprehensive characterization was performed in A. thaliana (Cardon et al., 1997) in order to explore their exact function in plants. Like all TFs that have been discovered up to date, SBP proteins were indicated to play crucial roles in the expressional regulation of genes that are involved in many important processes related to plant development and defence response (Unte et al., 2003; Zhang et al., 2007; Wu and Poethig, 2006).

Genome-wide characterization and expression studies of $S B P$ genes have been conducted on a number of plant species including Betula pendula, Chlamydomonas, Oryza sativa, Zea mays, Populus trichocarpa, Lycopersicon esculentum L., Malus $\times$ domestica Borkh., Salvia miltiorrhiza, Gossypium hirsutum, Arachis hypogaea L., Petunia, Capsicum annuum L., and Phyllostachys edulis (Chuck et al., 2010; Kropat et al., 2005; Lannenpaa et al., 2004; Li et al., 2013, 2016; Lu et al., 2011; Pan et al., 2017; Preston et al., 2016; Salinas et al., 2012; Xie et al., 2006; Zhang et al., 2016, 2014; Zhang et al., 2015). Nonetheless, the SBP proteins in Eucalyptus grandis, a tall forest tree in the Myrtaceae known as the flooded gum or rose gum, have not been identified and characterized despite the fact its genome was sequenced in 2014 (Myburg et al., 2014). 
Eucalyptus grandis (E. grandis) is a plantation crop which spreads widely in tropics and subtropics areas. It is commonly found in nature in Australia, and it is considered an important plant for plant scientist because, of its extreme ability to adapt to both climate and soil (Robinson et al., 2006). Moreover, there is a wide range of uses for E. grandis in farm; specialty products (flowers generate nectar for honey production), urban (used for ornamental purposes), wildlife value (its flowers attracts birds) and wood products including: pulpwood, boat building, boxes, flooring, heavy construction, fuelwood, industrial charcoal, panelling and timber for furniture etc (dos Santos et al., 2004; Nautiyal and Couto, 1984; Hardie and Wood, 1973; Dye, 2013).

Due to its importance in a wide range of use for the industry, and its ability to adapt to extreme soil and climate conditions, our aim was to identify and characterize SBP proteins in E. grandis which are important $\mathrm{TF}$ family for the plant developmental processes. Accordingly, 16 Egrandis_SBP members were identified and comprehensive analyses of the sequence phylogeny, genomic organization, exon-intron region of gene, conserved protein motifs, gene duplication events, and expression analysis were performed.

\section{Materials and methods}

\section{Identification of SBP genes in E. grandis genome}

E. grandis of SBP protein sequences were retrieved from Phytozome database v12.1 (www.phytozome.net) using keywords in the search with Pfam Accession Number (PF03110) obtained from Pfam Database (http://pfam.xfam.org). BLASTP and BLASTX searches (National Center for Biotechnology Information [NCBI]: http://www.ncbi.nlm.nih.gov) were used to confirm Egrandis_SBP proteins. Nonredundant sequences were obtained using decrease redundancy tool (http://web.expasy.org/decrease_redundancy/). SBP domains in non-redundant sequences were checked by HMMER (http://www.ebi.ac.uk). The solid and chemical traits of SBP proteins in E. grandis were identified using the ProtParam tools (http://web.expasy.org/protparam/) such as: the theoretical isoelectric point (pI), number of amino acids, and molecular weight (Da).

\section{Phylogenetic analysis, physical location, conserved motifs of Egrandis_SBP genes, gene structure and gene duplication events}

Chromosomal locations and CDS sizes (bp) were identified by using Phytozome database v12.1. The Egrandis_SBP genes were mapped with MapChart (Voorrips, 2002). Multiple sequence alignment of aminoacid sequences of Egrandis_SBP proteins was conducted with ClustalW Phylogenetic analysis were performed using MEGA v7 (Tamura et al., 2013; Buyuk and Aras, 2016) and Neighbor-joining (NJ) algorithm with 1000 replicated-bootstrap value.

Egrandis_SBP protein sequences of the conserved motifs were identified using MEME (Multiple Expectation Maximization for Motif Elucidation; http://memesuite.org/) (Bailey et al., 2006; Buyuk et al., 2016; Inal et al., 2017; Ilhan et al., 2018). The limits for maximum number of motifs and minimum/maximum width were adjusted to; 20 and 2, 50, respectively. Motif sites were among 2 and 300. Site distribution was set as any number of repetitions. The described conserved motifs were examined in InterProscan with default adjusting (Quevillon et al., 2005). 
Gene Structure Display Server program tool (GSDS; http://gsds.cbi.pku.edu.cn/) was used (Guo et al., 2007) to predict the exon/intron organization of the Egrandis_SBP genes. Genomic DNA sequences and coding sequences of Egrandis_SBP genes were utilized.

Segmental duplicate gene pairs were examined on the Plant Genome Duplication Database server (http://chibba.agtec.uga.edu/duplication/index/locus), with a display range of $100 \mathrm{~kb}$. The nonsynonymous rates $(\mathrm{Ka})$, synonymous rates (Ks) and developmental constraints $(\mathrm{Ka} / \mathrm{Ks})$ with the duplicated pairs of Egrandis_SBPs were evaluated using CODEML program in PAML (Yang, 2007).

\section{Synteny analysis}

E. grandis and A. thaliana, E. grandis and V. vinifera of orthologue $S B P$ genes were identified with Plant Genome Duplication Database (PGDD; http://chibba.agtec.uga.edu/duplication/) (Lee et al., 2013). Then, the protein sequences of orthologue were retrieved from Phytozome v12.1. The obtained synteny map was created using iTAK - Plant Transcription factor \& Protein Kinase Identifier and Classifier (http://itak.feilab.net/cgi-bin/itak/index.cgi) (Zheng et al., 2016).

\section{Gene expression analysis in silico}

The expression levels of Egrandis_SBP genes were examined in special tissue libraries of plants at different stages of; shoot tips, young leaf, xylem, mature leaf, immature xylem and phloem. They were retrieved from Phytozome Database v12.1 (http://phytozome.jgi.doe.gov/pz/portal.html\#!info?alias=Org_Pvulgaris). $\quad$ FPKM (expected number of fragments per kilobase of transcript sequence per millions base pairs sequenced) units were used for the expression levels in silico. FPKM values were $\log 2$ transformed and the heatmap was produced with the algorithm CIMMiner (http://discover.nci.nih.gov/cimminer).

\section{Results and discussion}

\section{Identification of SBP gene family in E. grandis}

Sequences of $S B P$ proteins in the E. grandis genome were downloaded from Phytozome database v12.1 (www.phytozome.net) using keywords in the search with Pfam Accession Number (PF03110) retrieved from Pfam Database (http://pfam.xfam.org/). Subsequently, SBP domains were analyzed by performing a search in the HMMER and Pfam databases in candidate Egrandis_SBP proteins, and the redundant sequences were discarded after obtaining confirmation. A total of 16 candidate SBP genes in E. grandis genome were discovered and given in Table 1 which includes information about chromosomal location, amino acid (length), molecular weight, number of isoelectric point $(\mathrm{pI})$ and instability index.

As shown in Table 1 and Figure 1, all of the non-redundant Egrandis_SBP genes were distributed on 7 out of 11 chromosomes of $E$. grandis. While the lowest number of Egrandis_SBP genes was observed on chromosome 4 (one Egrandis_SBP gene), the highest number was found on chromosome 11 (4 Egrandis_SBP genes) (Fig. 1). The length of Egrandis_SBP proteins extended from 147 (Egrandis_SBP_8) to 1078 (Egrandis_SBP_10) amino acids (aa). PI values of Egrandis_SBP proteins were among 5.77 (Egrandis_SBP_9) and 9.50 (Egrandis_SBP_5) ranging from acidic to alkaline 
while the molecular weight of Egrandis_SBPs was between $21.277 \mathrm{kDa}$ (Egrandis_SBP_11) and $119.285 \mathrm{kDa}$ (Egrandis_SBP_10) (Table 1). SBP, which is a plant specific transcription gene family, was detected and classified in various species thus far, such species include: A. thaliana (Rhoades et al., 2002), Orzya sativa (Xie et al., 2006), Lycopersicon esculentum L. (Salinas et al., 2012), V. vinifera (Hou et al., 2013), Citrus (Shalom et al., 2015), Triticum L. (Wang et al., 2015), Zea mays (Mao et al., 2016), Gossypium raimondii (Ali et al., 2017), Petunia (Zhou et al., 2018), Fragaria vesca, Pyrus bretschneideri, Prunus persica and Prunus mume (Abdullah et al., 2018). Nevertheless, this is the first comprehensive report on identification and characterization of $S B P$ genes in E. grandis.

Table 1. Information of 16 Egrandis_SBP proteins

\begin{tabular}{c|l|l|c|c|c|c|c}
\hline \multicolumn{1}{c|}{ Gene ID } & Gene name & \multicolumn{1}{|c|}{ Locations } & aa & $\begin{array}{c}\text { mw } \\
\text { (kDa) }\end{array}$ & pI & $\begin{array}{c}\text { Instability } \\
\text { index }\end{array}$ & Classifies \\
\hline Egrandis_SBP_1 & Eucgr.A01019 & Chr01:30283917..30289641 forward & 984 & 109.125 & 5.79 & 56.75 & Unstable \\
Egrandis_SBP_2 & Eucgr.A02441 & Chr01:39752248..39757521 reverse & 390 & 41.273 & 9.12 & 54.92 & Unstable \\
Egrandis_SBP_3 & Eucgr.B00631 & Chr02:6573009..6576407 reverse & 524 & 57.179 & 8.74 & 55.34 & Unstable \\
Egrandis_SBP_4 & Eucgr.B03500 & Chr02:54998894..55003285 reverse & 488 & 53.532 & 8.67 & 53.61 & Unstable \\
Egrandis_SBP_5 & Eucgr.B03518 & Chr02:55118387..55120136 reverse & 318 & 34.533 & 9.50 & 53.22 & Unstable \\
Egrandis_SBP_6 & Eucgr.D02505 & Chr04:39040236..39042737 forward & 348 & 38.354 & 8.45 & 64.98 & Unstable \\
Egrandis_SBP_7 & Eucgr.E01600 & Chr05:18228156..18230663 forward & 367 & 38.759 & 9.07 & 72.79 & Unstable \\
Egrandis_SBP_8 & Eucgr.E03260 & Chr05:53739864..53743190 reverse & 147 & 16.977 & 6.00 & 88.37 & Unstable \\
Egrandis_SBP_9 & Eucgr.B01228 & Chr06:24482430..24488179 forward & 821 & 91.221 & 5.77 & 55.35 & Unstable \\
Egrandis_SBP_10 & Eucgr.F01828 & Chr06:24482430..24488179 forward & 1078 & 119.285 & 7.11 & 58.38 & Unstable \\
Egrandis_SBP_11 & Eucgr.F03303 & Chr06:44594386..44595751 reverse & 186 & 21.277 & 8.86 & 69.09 & Unstable \\
Egrandis_SBP_12 & Eucgr.H04114 & Chr08:55717528..55724988 reverse & 1005 & 112.303 & 6.39 & 49.39 & Unstable \\
Egrandis_SBP_13 & Eucgr.K01046 & Chr11:13456169..13458136 forward & 236 & 26.056 & 8.66 & 64.51 & Unstable \\
Egrandis_SBP_14 & Eucgr.K01828 & Chr11:23807022..23809835 reverse & 376 & 39.879 & 9.12 & 59.39 & Unstable \\
Egrandis_SBP_15 & Eucgr.K02545 & Chr11:33320448..33325312 reverse & 551 & 59.583 & 6.83 & 50.07 & Unstable \\
Egrandis_SBP_16 & Eucgr.K02708 & Chr11:34626111..34629250 forward & 363 & 39.804 & 8.96 & 55.21 & Unstable \\
\hline
\end{tabular}

Based on the importance of gene duplications in the evolution of gene families in plants, the gene duplication events of putative SBP genes in E. grandis genome have been examined in this study. Our analysis identified three duplicated gene couple (Egrandis_SBP_2/ Egrandis_SBP_4, Egrandis_SBP_8/ Egrandis_SBP_13, Egrandis_SBP_11/ Egrandis_SBP_13 and Egrandis_SBP_3/ Egrandis_SBP_15) among eight identified Egrandis_SBP genes (Fig. 1). The $\mathrm{Ka} / \mathrm{Ks}$ ratios between these duplication gene couples were found to be lower than ' 1 ' which suggests that: natural selection has occurred during segmental duplication events (Juretic et al., 2005).

Likewise, many segmental duplications of SBP genes have been detected in $A$. thaliana (AtSPL10/AtSPL11, AtSPL4/AtSPL5, AtSPL1/AtSPL12) and O. sativa (OsSBP10/OsSBP5, OsSBP11/OsSBP4, OsSBP12/OsSBP3) (Blanc and Wolfe, 2004; Bowers et al., 2003; Paterson et al., 2004; Wang et al., 2005). Besides segmental duplication events, some plant species including Malus $\times$ domestica Borkh (Li et al., 2013), V. vinifera (Hou et al., 2013), F. vesca, Pyrus bretschneideri, P. persica and $P$. mume (Abdullah et al., 2018) have demonstrated to have tandem duplication events either. 


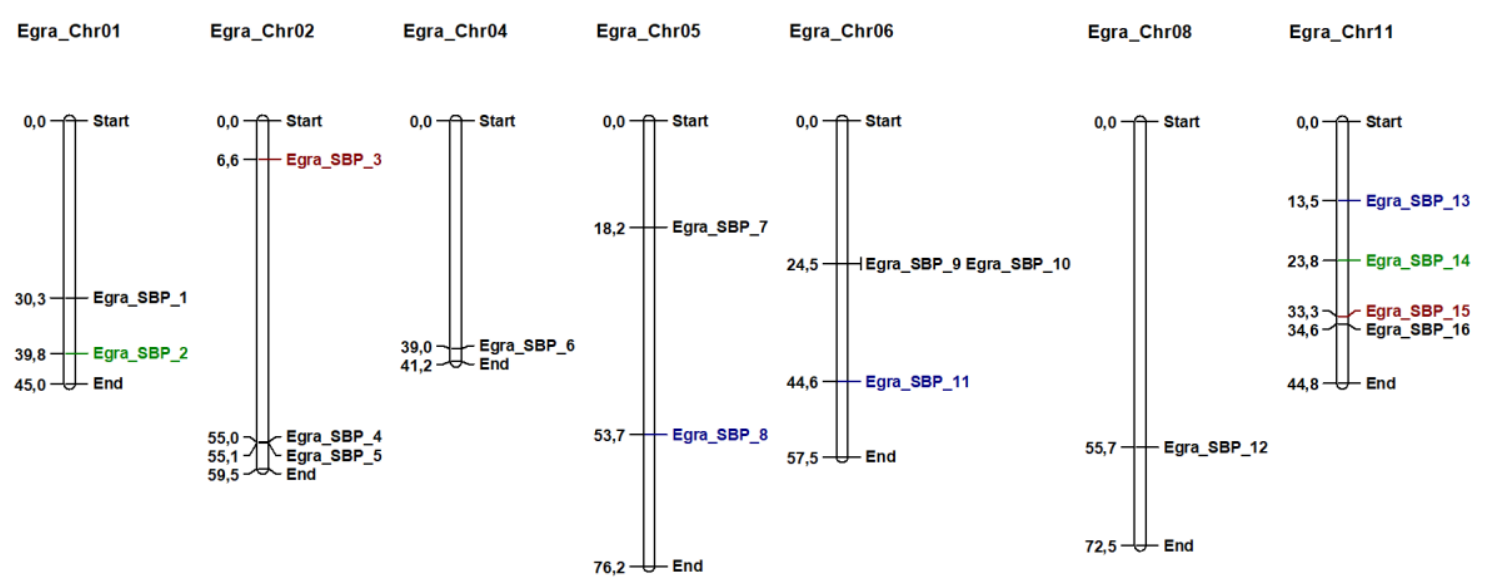

Figure 1. Distribution of Egrandis_SBP genes on chromosomes of Eucalyptus grandis

\section{Phylogenetic analysis, gene structure and conserved motifs of Egrandis_SBPS}

To discover the relationships between Egrandis_SBP proteins, a phylogenetic tree of SBP proteins in E. grandis, A. thaliana and $V$. vinifera was constructed using neighborjoining (NJ) method with bootstrapping 1000 times (Fig. 2). Egrandis_SBPs were clustered into eight groups from A to D4 (Fig. 2). Group C2 was the largest group containing 18 SBP members, that is almost $34 \%$ of the total SBP proteins in the tree. And a minimum of one member of Egrandis_SBP proteins have made a contribution to each group, except for the Group A which has only one SBP protein from $V$. vinifera (Fig. 2). Egrandis_SBP proteins were clustered with the same number (7 from each) of $A$. thaliana and $V$. vinifera SBP proteins in Group C2. In contrast, any of $A$. thaliana were clustered with SBP proteins of $E$. grandis and $V$. vinifera in Group C1 suggesting that these genes may have been lost during evolution in A. thaliana. As previously declared by Abdullah et al. (2018), this kind of loss and birth of SBP genes which are specific to species might cause divergence in these genes in terms of functionality (Abdullah et al., 2018). In addition, similar coding and exon-intron sequences were observed in SBP genes which were found in the same subgroup of the phylogenetic tree (Fig. 2).

Similarly, phylogenetic trees of SBP proteins from several plant species including rice (Xie et al., 2006), A. thaliana (Guo et al., 2008), Z. mays (Chuck et al., 2010), L. esculentum (Salinas et al., 2012), Malus slyvestris (Li et al., 2013) and Phyllostachys edulis (Pan et al., 2017) were also divided into eight groups in accordance with the phylogenetic tree of SBP proteins from $E$. grandis.

To investigate conserved motifs in Egrandis_SBP proteins, MEME (v4.12.0) were used, and a total of 15 conserved motifs were described (Fig. 3 and Table Al in the Appendix). The lengths of identified motifs were between 11 and 50 amino acids and all identified Egrandis_SBP proteins were found to have Motif 1, 2 and 3, which constitute the SBP domain (Fig. 3). Some of the other SBP motifs were only found in some Egrandis_SBP proteins, suggesting that these motifs may be provide by a specific function of these proteins (Fig. 3). 


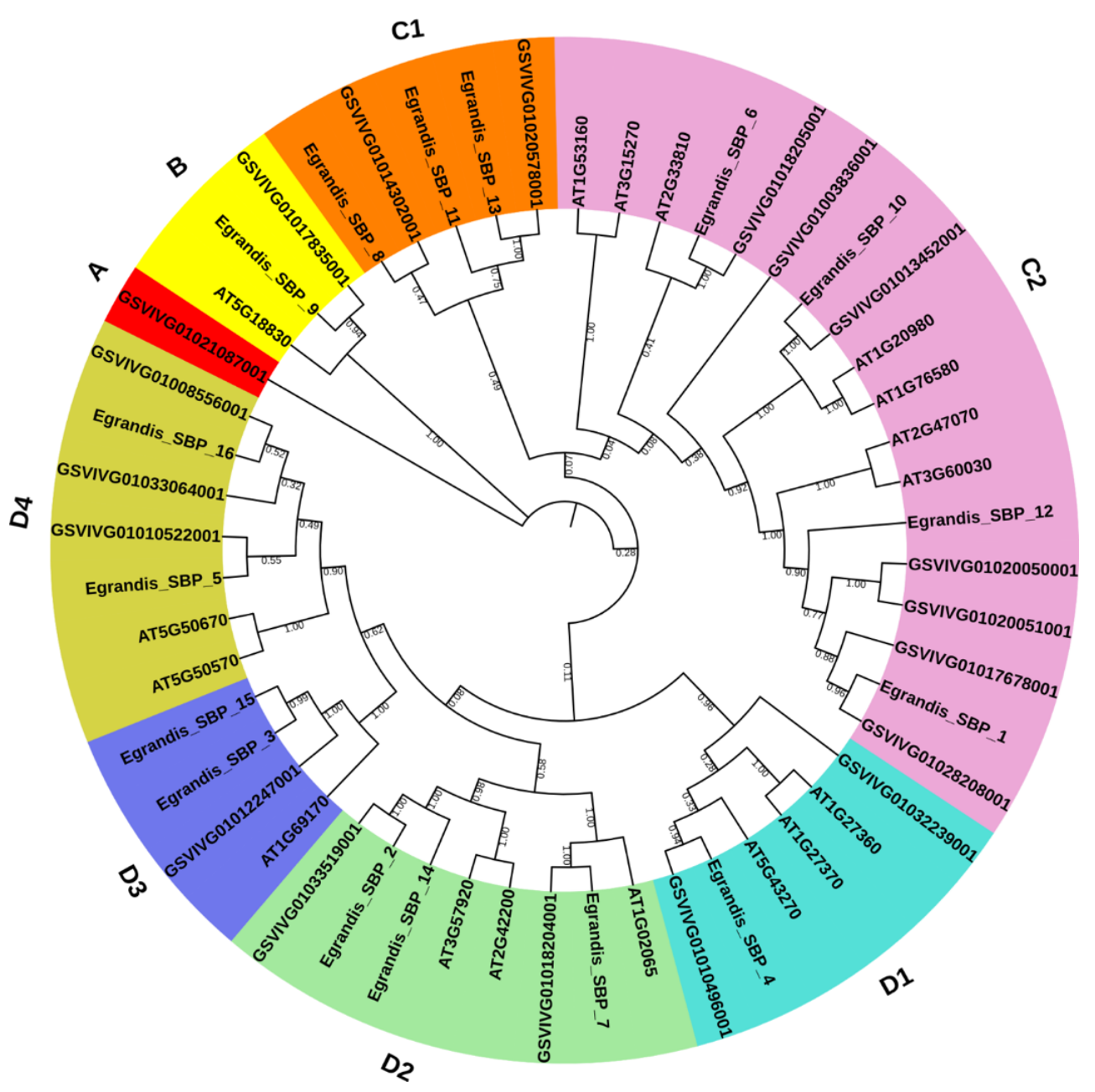

Figure 2. Phylogenetic tree based on the conserved SBP domains alignment of 16

Egrandis_SBP predicted proteins, 17 A. thaliana SBP proteins and 19 Vitis vinifera SBP proteins, respectively. The tree was generated with MEGA $v 7.0$ software, using the Neighborjoining (NJ) method, and bootstrap values were calculated with 1000 replicates. Identified groups are shown on the outside of the circle

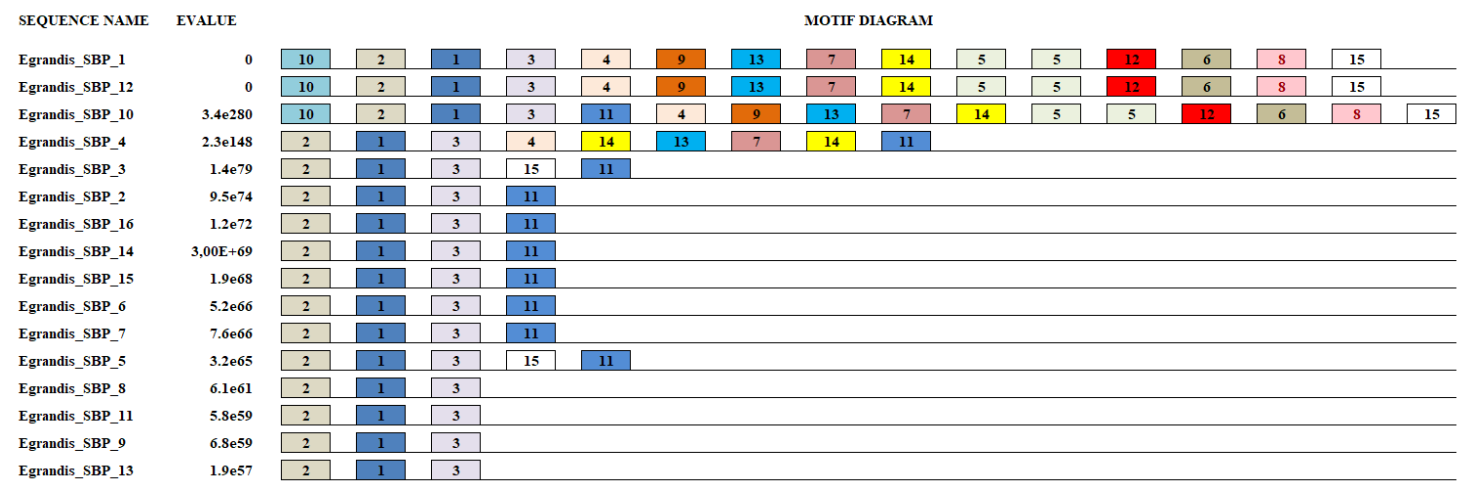

Figure 3. Distribution of conserved motif of SBP genes in E. grandis. Full explanation of the motifs were given as seen in Table Al in the Appendix 
The SBP domain were shown to form two zinc fingers in all Egrandis_SBP proteins and zinc finger 1 (Cys-Cys-His-Cys) was composed of Motif 1 while Motif 2 and 3 were involved in the construction of zinc finger 2 (Cys-Cys-Cys-His) as shown in Figure 4. These zinc binding sites were shown to be essential for SBP domain however they have been reported as having different structures than other zinc binding structures by Yamasaki et al. (2004) and thus, they are known as a novel zinc-binding motif (Yamasaki et al., 2004).
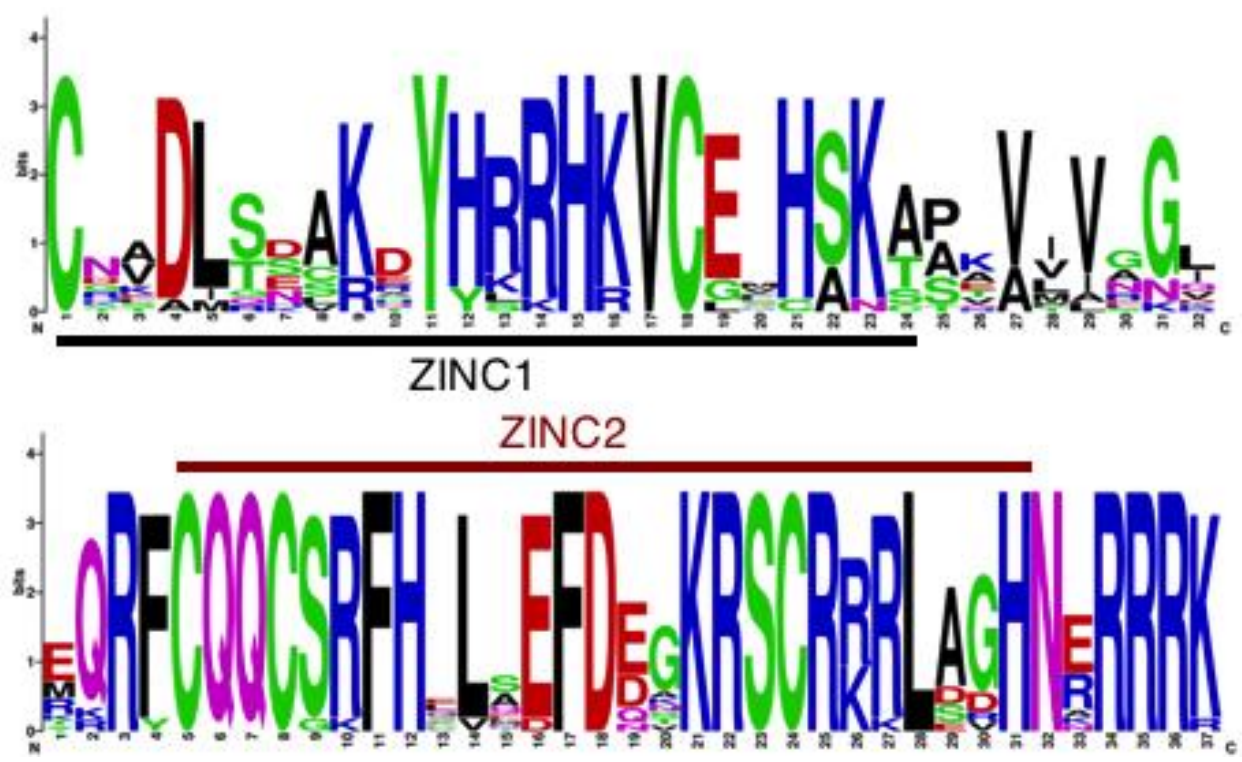

Figure 4. Domain compositions of Egrandis_SBP genes. Thirteen Egrandis_SBP genes have both the characteristics of ZINC1 (Cys-Cys-His-Cys) and ZINC2 (Cys-Cys-Cys-His). The bit score represents the information content for each position in the sequence

Gene structures of 16 E. grandis SBP gene were investigated and the estimated number of exons among all genes extended from 2 (Egrandis_SBP_8) to 11 (Egrandis_ $S B P \_$) (Fig. 5). This varied numbers of exons in $E$. grandis $S B P$ family genes by gain or loss of exon(s)/intron(s) might have occurred during evolution of Egrandis_SBP genes.

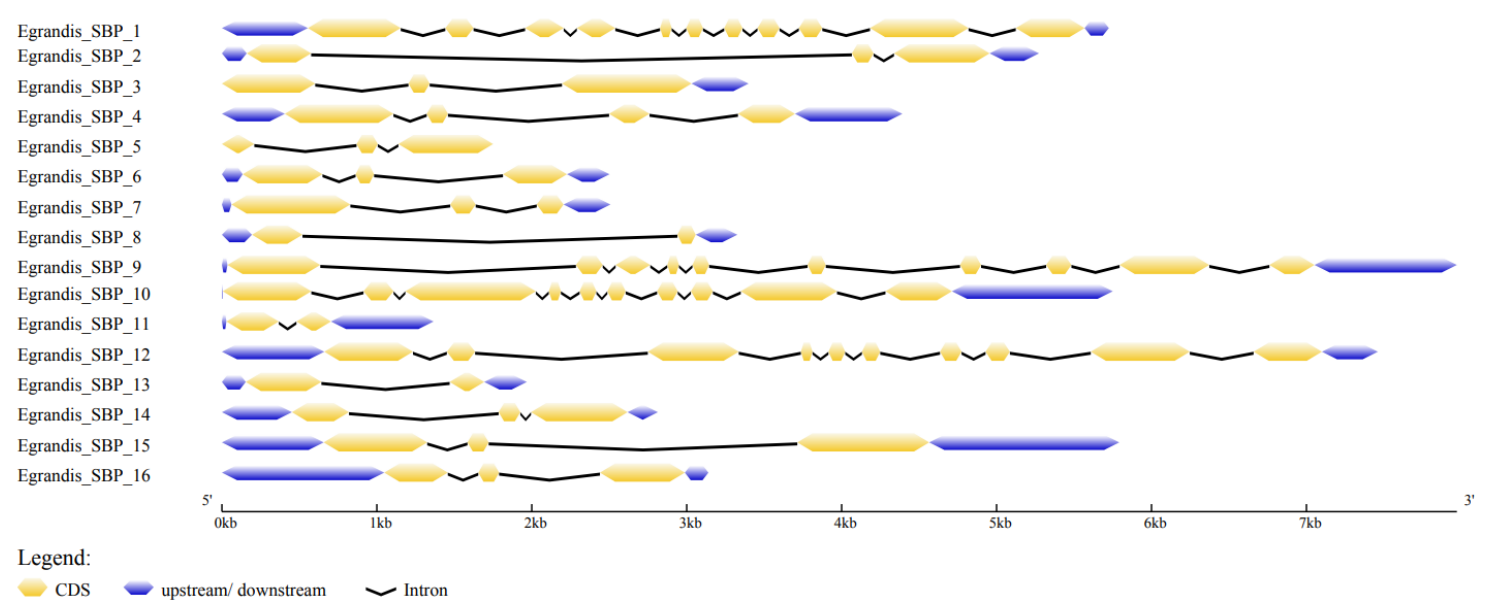

Figure 5. Gene structure of SBP genes in E. grandis 
Comparative and synteny events among SBP genes of E. grandis, A. thaliana and $V$. vinifera

SBP protein sequences from E. grandis, A. thaliana and Vitis vinifera were subjected to comparative synteny analysis, to calculate evolutionary relationship of the SBP gene family between these species (Fig. 6). A total of 16 SBP proteins from E. grandis, 12 from $A$. thaliana, and 10 from $V$. vinifera was used to perform the synteny analysis. According to the synteny analysis results, homologs of $E$. grandis genes were found in corresponding syntenic blocks of A. thaliana and V. vinifera (Fig. 6). In terms of coevaluation of gene duplications and synteny analyses of Egrandis_SBP genes, we can conclude from here, that both of these events might contribute to the evolutionary expansion of SBP genes in E. grandis genome (Figs. 1 and 6 ).

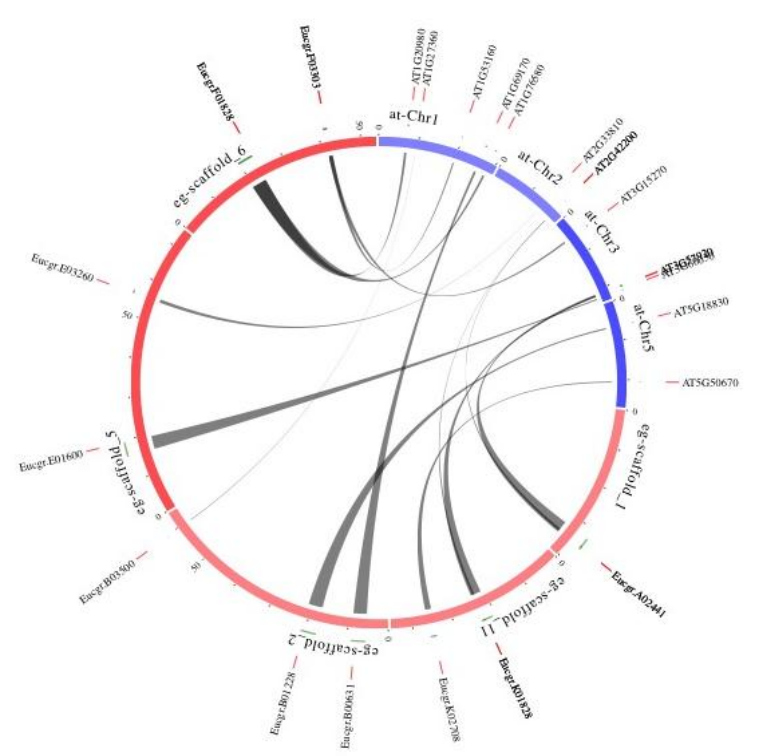

A

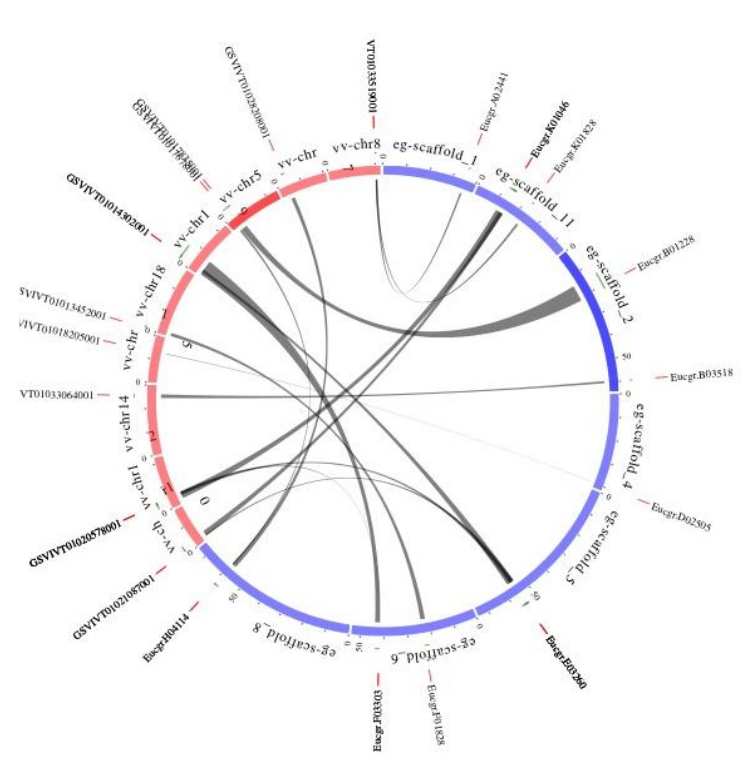

B

Figure 6. Genome wide synteny analysis of SBP genes. A. Comparative map between E. grandis and A. thaliana. B. Comparative map between $E$. grandis and V. vinifera 


\section{Expression profiles of Egrandis_SBPs in different tissues}

In this study, a common mRNA analysis of Egrandis_SBP genes were performed via publicly available expression data in Phytozome v12.1 online plant genomics resource (https://phytozome.jgi.doe.gov). The heatmap shows the expression variance of identified 16 Egrandis_SBP genes in different plant tissues (Fig. 7).

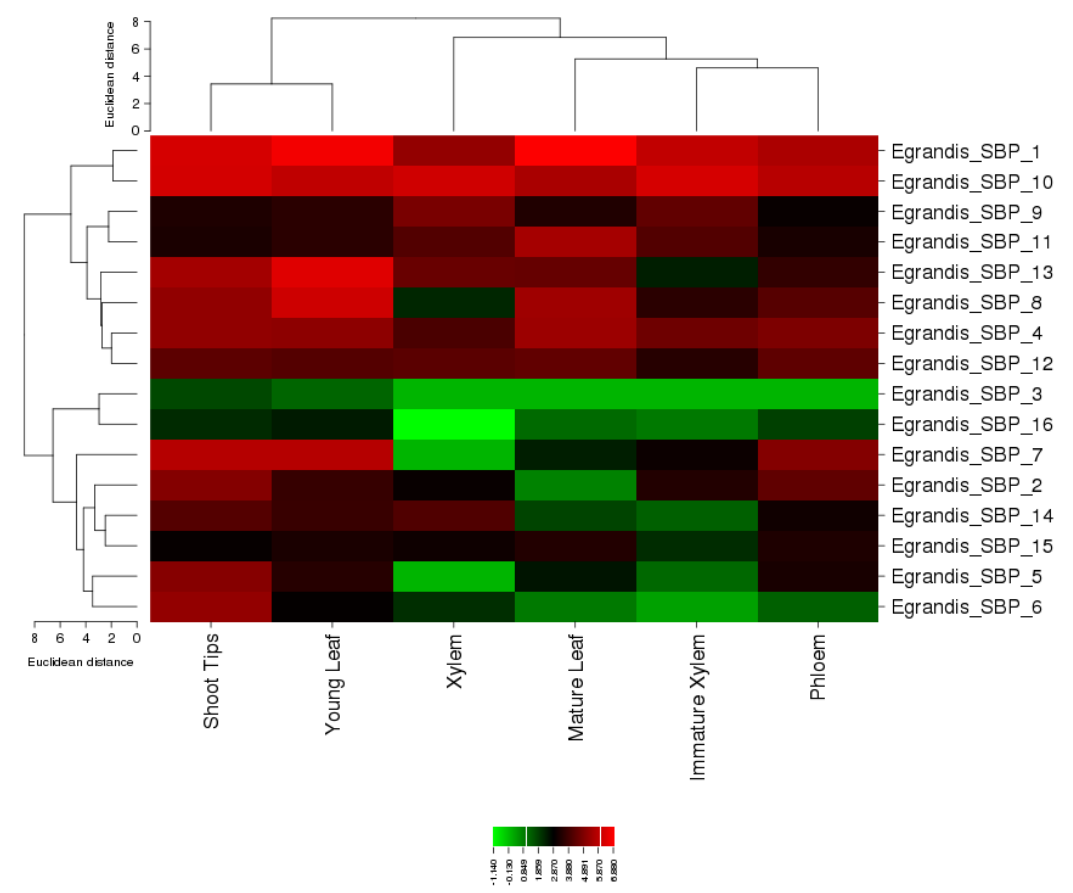

Figure 7. Expression profiling of E. grandis SBP genes in shoot tips, young leaf, xylem, mature leaf, immature leaf and phloem tissues. Green and red colors indicate low-expression and highexpression, respectively

As seen in the Figure 7, Egrandis_SBP_1, -10, -9, -11, -13, -8, -4 and -12 genes revealed relatively high expression levels in almost all tissues including shoot tips, young leaf, xylem, mature leaf, immature xylem and phloem. However, Egrandis_SBP_2, -3, -5, -6, -7, $-14,-15$ and -16 genes constituted relatively low expression levels in all tissues except for: shoot tips and young leaf (Fig. 7). In short, a conclusion can be drawn from the heatmap, that most of the Egrandis_SBP genes were highly expressed in all examined tissues of E. grandis.

\section{Conclusions}

The study herein, provides a comprehensive genome-wide identification of SBP genes in E. grandis. A total of $16 \mathrm{SBP}$ genes were identified and were labelled as: Egrandis_1 to Egrandis_16. They were sorted based on their chromosomal locations. To get insight into their biological functions in the genome of E. grandis, several analyses were conducted using many online and offline bioinformatic tools and genome databases. This study being the first study regarding the identification of SBP genes in E. grandis, it can be considered as a useful resource for the future studies regarding SBP genes in either in E. grandis or comparative different plant species. 


\section{REFERENCES}

[1] Abdullah, M., Cao, Y., Cheng, X., Shakoor, A., Su, X., Gao, J., Cai, Y. (2018): Genomewide analysis characterization and evolution of SBP genes in Fragaria vesca, Pyrus bretschneideri, Prunus persica and Prunus mume. - Frontiers in Genetics 9: 64. DOI: 10.3389/fgene.2018.00064.

[2] Ali, M. A., Alia, K. B., Atif, R. M., Rasul, I., Nadeem, H. U., Shahid, A., Azeem, F. (2017): Genome-wide identification and comparative analysis of squamosa-promoter binding proteins (Sbp) transcription factor family in Gossypium raimondii and Arabidopsis thaliana. - Pakistan Journal of Botany 49: 1113-1126.

[3] Bailey, T. L., Williams, N., Misleh, C., Li, W. W. (2006): MEME: discovering and analyzing DNA and protein sequence motifs. - Nucleic Acids Research 34: W369-W373.

[4] Blanc, G., Wolfe, K. H. (2004): Widespread paleopolyploidy in model plant species inferred from age distributions of duplicate genes. - The Plant Cell 16(7): 1667-1678.

[5] Bowers, J. E., Chapman, B. A., Rong, J., Paterson, A. H. (2003): Unravelling angiosperm genome evolution by phylogenetic analysis of chromosomal duplication events. - Nature 422(6930): 433-438.

[6] Buyuk, I., Aras, S. (2016): Genome-wide in silico identification, characterization and transcriptional analysis of the family of growth-regulating factors in common bean (Phaseolus vulgaris L.) subjected to PEG-induced drought stress. - Archives of Biological Science 69(1): 5-14.

[7] Buyuk, I., Inal, B., Ilhan, E., Tanriseven, M., Aras, S., Erayman, M. (2016): Genomewide identification of salinity responsive HSP70s in common bean. - Molecular Biology Reports 43(11): 1251-1266.

[8] Cardon, G. H., Hohmann, S., Nettesheim, K., Saedler, H., Huijser, P. (1997): Functional analysis of the Arabidopsis thaliana SBP-box gene SPL3: a novel gene involved in the floral transition. - Plant J 12(2): 367-377.

[9] Chuck, G., Whipple, C., Jackson, D., Hake, S. (2010): The maize SBP-box transcription factor encoded by tasselsheath4 regulates bract development and the establishment of meristem boundaries. - Development 137: 1585-1585.

[10] Dos Santos, P. E. T., Geraldi, I. O., Garcia, J. N. (2004): Estimates of genetic parameters of wood traits for sawn timber production in Eucalyptus grandis. - Genet Mol Biol 27(4): 567-573.

[11] Dye, P. (2013): A review of changing perspectives on Eucalyptus water-use in South Africa. - Forest Ecol Manag 301: 51-57.

[12] Guo, A., Zhu, Q., Chen, X., Luo, J. (2007): GSDS: a gene structure display server. - Yi chuan = Hereditas 29: 1023-1026.

[13] Guo, A. Y., Zhu, Q. H., Gu, X., Ge, S., Yang, J., Luo, J. (2008): Genome-wide identification and evolutionary analysis of the plant specific SBP-box transcription factor family. - Gene 418(1-2): 1-8.

[14] Hardie, A. D. K., Wood, A. A. (1973): Eucalyptus grandis timber from plantations in Zambia. - Commonw Forest Rev 52(152): 153-159.

[15] Hou, H. M., Li, J., Gao, M., Singer, S. D., Wang, H., Mao, L. Y., Fei, Z. J., Wang, X. P. (2013): Genomic organization, phylogenetic comparison and differential expression of the SBP-box family genes in grape. - Plos One 8.

[16] Inal, B., Buyuk, I., Ilhan, E., Aras, S. (2017): Genome wide analysis of Phaseolus vulgaris $\mathrm{C} 2 \mathrm{C} 2-\mathrm{YABBY}$ transcription factors under salt stress conditions. -3 Biotech 7(5): 302.

[17] Ilhan, E., Buyuk, I., Inal, B. (2018): Transcriptome-scale characterization of salt responsive bean TCP transcription factors. - Gene 5(642): 64-73.

[18] Juretic, N., Hoen, D. R., Huynh, M. L., Harrison, P. M., Bureau, T. E. (2005): The evolutionary fate of MULE-mediated duplications of host gene fragments in rice. Genome Research 15: 1292-1297. 
[19] Klein, J., Saedler, H., Huijser, P. (1996): A new family of DNA binding proteins includes putative transcriptional regulators of the Antirrhinum majus floral meristem identity gene SQUAMOSA. - Mol Gen Genet 250(1): 7-16.

[20] Kropat, J., Tottey, S., Birkenbihl, R. P., Depege, N., Huijser, P., Merchant, S. (2005): A regulator of nutritional copper signaling in Chlamydomonas is an SBP domain protein that recognizes the GTAC core of copper response element. - Proceedings of the National Academy of Sciences of the United States of America 102: 18730-18735.

[21] Lannenpaa, M., Janonen, I., Holtta-Vuori, M., Gardemeister, M., Porali, I. and Sopanen, T. (2004): A new SBP-box gene BpSPL1 in silver birch (Betula pendula). - Physiologia Plantarum 120: 491-500.

[22] Lee, T. H., Tang, H. B., Wang, X. Y., Paterson, A. H. (2013): PGDD: a database of gene and genome duplication in plants. - Nucleic Acids Research 41: D1152-D1158.

[23] Li, J., Hou, H. M., Li, X. Q., Xiang, J., Yin, X. J., Gao, H., Zheng, Y., Bassett, C. L., Wang, X. P. (2013): Genome-wide identification and analysis of the SBP-box family genes in apple (Malus $\times$ domestica Borkh.). - Plant Physiology and Biochemistry 70: 100-114.

[24] Li, M., Zhao, S. Z., Zhao, C. Z., Zhang, Y., Xia, H., Lopez-Baltazar, J., Wan, S. B., Wang, X. J. (2016): Cloning and characterization of SPL-family genes in the peanut (Arachis hypogaea L.). - Genetics and Molecular Research 15. DOI: 10.4238/gmr.15017344.

[25] Lu, S. F., Yang, C. M., Chiang, V. L. (2011): Conservation and diversity of MicroRNAassociated copper-regulatory networks in Populus trichocarpa. - Journal of Integrative Plant Biology 53: 879-891.

[26] Mao, H. D., Yu, L. J., Li, Z. J., Yan, Y., Han, R., Liu, H., Ma, M. (2016): Genome-wide analysis of the SPL family transcription factors and their responses to abiotic stresses in maize. - Plant Gene 6: 1-12.

[27] Myburg, A. A., Grattapaglia, D., Tuskan, G. A., Hellsten, U., Hayes, R. D., Grimwood, J., Jenkins, J., Lindquist, E. et al. (2014): The genome of Eucalyptus grandis. - Nature 510(7505): 356-362.

[28] Nautiyal, J. C., Couto, L. (1984): The nature and uses of the timber production function Eucalyptus grandis in Brazil. - Forest Sci 30(3): 761-773.

[29] Pan, F., Wang, Y., Liu, H. L., Wu, M., Chu, W. Y., Chen, D. M., Xiang, Y. (2017): Genome-wide identification and expression analysis of SBP-like transcription factor genes in Moso Bamboo (Phyllostachys edulis). - BMC Genomics 18.

[30] Paterson, A. H., Bowers, J. E., Chapman, B. A. (2004): Ancient polyploidization predating divergence of the cereals, and its consequences for comparative genomics. Proceedings of the National Academy of Sciences of the United States of America 101(26): 903-9908.

[31] Preston, J. C., Jorgensen, S. A., Orozco, R., Hileman, L. C. (2016): Paralogous SQUAMOSA PROMOTER BINDING PROTEIN-LIKE (SPL) genes differentially regulate leaf initiation and reproductive phase change in petunia. - Planta 243: 429-440.

[32] Quevillon, E., Silventoinen, V., Pillai, S., Harte, N., Mulder, N., Apweiler, R., Lopez, R. (2005): InterProScan: protein domains identifier. - Nucleic Acids Research 33: W116W120.

[33] Rhoades, M. W., Reinhart, B. J., Lim, L. P., Burge, C. B., Bartel, B., Bartel, D. P. (2002): Prediction of plant microRNA targets. - Cell 110: 513-520.

[34] Robinson, N., Harper, R. J., Smettem, K. R. J. (2006): Soil water depletion by Eucalyptus spp. integrated into dryland agricultural systems. - Plant and Soil 286(1): 41-151.

[35] Salinas, M., Xing, S. P., Hohmann, S., Berndtgen, R., Huijser, P. (2012): Genomic organization, phylogenetic comparison and differential expression of the SBP-box family of transcription factors in tomato. - Planta 235: 1171-1184.

[36] Shalom, L., Shlizerman, L., Zur, N., Doron-Faigenboim, A., Blumwald, E., Sadka, A. (2015): Molecular characterization of SQUAMOSA PROMOTER BINDING PROTEIN- 
LIKE (SPL) gene family from Citrus and the effect of fruit load on their expression. Frontiers in Plant Science 6.

[37] Tamura, K., Stecher, G., Peterson, D., Filipski, A., Kumar, S. (2013): MEGA6: Molecular Evolutionary Genetics Analysis Version 6.0. - Molecular Biology and Evolution 30: 2725-2729.

[38] Unte, U. S., Sorensen, A. M., Pesaresi, P., Gandikota, M., Leister, D., Saedler, H., Huijser, P. (2003): SPL8, an SBP-Box gene that affects pollen sac development in Arabidopsis. - Plant Cell 15: 1009-1019.

[39] Voorrips, R. E. (2002): MapChart: Software for the graphical presentation of linkage maps and QTLs. - Journal of Heredity 93: 77-78.

[40] Wang, B. N., Geng, S. F., Wang, D., Feng, N., Zhang, D. D., Wu, L., Hao, C. Y., Zhang, X. Y., Li, A. L., Mao, L. (2015): Characterization of SQUAMOSA PROMOTER BINDING PROTEIN-LIKE genes in wheat. - Journal of Plant Biology 58: 220-229.

[41] Wang, X., Shi, X., Hao, B., Ge, S., Luo, J. (2005): Duplication and DNA segmental loss in the rice genome: implications for diploidization. - The New Phytologist 165(3): 37946.

[42] Wu, G., Poethig, R. S. (2006): Temporal regulation of shoot development in Arabidopsis thaliana by miR156 and its target SPL3. - Development 133(18): 539-3547.

[43] Xie, K. B., Wu, C. Q., Xiong, L. Z. (2006): Genomic organization, differential expression, and interaction of SQUAMOSA promoter-binding-like transcription factors and microRNA156 in rice. - Plant Physiology 142: 280-293.

[44] Yamasaki, K., Kigawa, T., Inoue, M., Tateno, M., Yamasaki, T., Yabuki, T., Aoki, M., Seki, E., Matsuda, T., Nunokawa, E., Ishizuka, Y., Terada, T., Shirouzu, M., Osanai, T., Tanaka, A., Seki, M., Shinozaki, K., Yokoyama, S. (2004): A novel zinc-binding motif revealed by solution structures of DNA-binding domains of Arabidopsis SBP-family transcription factors. - Journal of Molecular Biology 337(1): 9-63.

[45] Yang, Z. H. (2007): PAML 4: Phylogenetic analysis by maximum likelihood. Molecular Biology and Evolution 24: 1586-1591.

[46] Zhang, H. X., Jin, J. H., He, Y. M., Lu, B. Y., Li, D. W., Chai, W. G., Khan, A., Gong, Z. H. (2016): Genome-wide identification and analysis of the SBP-Box family genes under Phytophthora capsici stress in pepper (Capsicum annuum L.). - Frontiers in Plant Science 7. DOI: $10.3389 /$ fpls.2016.00504.

[47] Zhang, L. S., Wu, B., Zhao, D. G., Li, C. L., Shao, F. J., Lu, S. F. (2014): Genome-wide analysis and molecular dissection of the SPL gene family in Salvia miltiorrhiza. - Journal of Integrative Plant Biology 56: 38-50.

[48] Zhang, X. H., Dou, L. L., Pang, C. Y., Song, M. Z., Wei, H. L., Fan, S. L., Wang, C. S., $\mathrm{Yu}$, S. X. (2015): Genomic organization, differential expression, and functional analysis of the SPL gene family in Gossypium hirsutum. - Molecular Genetics and Genomics 290: 115-126.

[49] Zhang, Y., Schwarz, S., Saedler, H., Huijser, P. (2007): SPL8, a local regulator in a subset of gibberellin-mediated developmental processes in Arabidopsis. - Plant Molecular Biology 63: 429-439.

[50] Zheng, Y., Jiao, C., Sun, H. H., Rosli, H. G., Pombo, M. A., Zhang, P. F., Banf, M., Dai, X. B., Martin, G. B., Giovannoni, J. J., Zhao, P. X., Rhee, S. Y., Fei, Z. J. (2016): iTAK: a program for genome-wide prediction and classification of plant transcription factors, transcriptional regulators, and protein kinases. - Molecular Plant 9: 1667-1670.

[51] Zhou, Q., Zhang, S., Chen, F., Liu, B., Wu, L., Li, F., Zhang, J., Bao, M., Liu, G. (2018): Genome-wide identification and characterization of the SBP-box gene family in Petunia. - BMC Genomics 19: 193. 


\section{APPENDIX}

Table A1. Sequence information of predicted motifs in Egrandis_SBP proteins

\begin{tabular}{|c|c|c|}
\hline Motif \# & Width & Best possible match \\
\hline$\# 1$ & 50 & YHRRHKVCEVHSKAPKVIVGGLEQRFCQQCSRFHELSEFDEGKRSCRRRL \\
\hline \#2 & 21 & GAQPPRCQVEGCNADLSDAKD \\
\hline \#3 & 13 & AGHNERRRKPPPE \\
\hline \#4 & 50 & RTGRIVFKLFGKDPNDFPLALRTQIFNWLSHSPTEMESYIRPGCIILTVY \\
\hline \#5 & 24 & KWLLHFAVERDCRALVKKLLDYJF \\
\hline \#6 & 41 & NDPQLVGIEAWKSARDASGQTPEDYAVLRGHYSYIHLVQKK \\
\hline$\# 7$ & 50 & DELQFLKFPCSIPKVCGRGFIEVENQGLPGSFFPFIVAEEEVCSEIRMLE \\
\hline \#8 & 28 & YRPAMLSMVAIAAVCVCVALLFKSLPEV \\
\hline \#9 & 50 & AWEELHGNLGSSLRKLLDVSDDDFWRTGWIYVRVQDKLAFVYNGQIVLGT \\
\hline \#10 & 21 & VEWDPNDWKWDGDLFVAKPLN \\
\hline \#11 & 19 & VSESSRALSLLSSQSQDSS \\
\hline \#12 & 21 & NFLFKPNAVGPAGLTPLHIAA \\
\hline \#13 & 48 & HNSPRJLSIRPIAISAGQSTEFVVKGFNLFQPATRLLCALEGKYLAQE \\
\hline \#14 & 11 & FINEIGWLLKR \\
\hline \#15 & 14 & GCLQPFRWEALDYG \\
\hline
\end{tabular}

